\title{
Estimation of Bite Angle Effect on the Electronic Structure of Cobalt-Phosphine Complexes: A QTAIM Study
}

\author{
Tamara Papp, László Kollár, and Tamás Kégl \\ Department of Inorganic Chemistry and János Szentágothai Research Center, \\ MTA-TKI Research Group for Selective Chemical Syntheses, University of Pécs, Ifjúság útja 6, Pécs 7624, Hungary
}

Correspondence should be addressed to Tamás Kégl; tkegl@gamma.ttk.pte.hu

Received 1 October 2013; Accepted 18 December 2013; Published 29 January 2014

Academic Editor: Daniel Glossman-Mitnik

Copyright (C) 2014 Tamara Papp et al. This is an open access article distributed under the Creative Commons Attribution License, which permits unrestricted use, distribution, and reproduction in any medium, provided the original work is properly cited.

The influence of bite angle in bisphosphine complexes has been modeled by DFT calculations employing the simple model compound $\mathrm{HCo}(\mathrm{CO})(\mathrm{PP})(\mathrm{PP}=$ Xantphos or two monophosphine ligands). The increase of the bite angle increases the strength of the $\mathrm{H}-\mathrm{Co}$ bond, whereas the $\mathrm{C}-\mathrm{O}$ bond in the carbonyl ligand is weakened revealing an increase also in the donor character. The model compound cis-[HCo(CO) $\left.\left(\mathrm{PPh}_{3}\right)_{2}\right]$ shows a flexibility both in terms of energy, and in terms of electronic structure upon the change of the $\mathrm{P}-\mathrm{Co}-\mathrm{P}$ angle, which can be a sign of the flexibility of $\mathrm{PPh}_{3}$ ligands in real reaction conditions.

\section{Introduction}

Catalytic hydroformylation of alkenes is one of the largest volume applications of homogeneous catalysts. In the recent decades the continued development of new P-donor ligands has resulted in significant advances in the selectivity of hydroformylation catalysts. An especially effective improvement in the control of catalyst regioselectivity involves the application of bulky diphosphines and diphosphites with wide bite angles [1-3]. In the rhodium catalyzed hydroformylation, particularly high regioselectivities were achieved employing bidentate diphosphines based on xanthene-like backbones, and it was found that the larger the bite angle, the greater the selectivity for the linear aldehydes [2]. Two examples of pioneering wide bite angle diphosphines are depicted in Scheme 1.

The understanding of fundamental aspects of transition metal-catalyzed reactions is profound for the discovery of new and more efficient catalysts. Computations play an increasingly important role in getting new insights in reaction mechanism by their ability to provide equilibrium geometries for transition states and high energy intermediates, as well as by the determination of electronic structure parameters of structures of importance.

Potential energy surfaces (PESs) are indispensable for studying reaction profiles and rates computationally [4]. For exploring a region of the PES the relaxed PES scan calculations are sometimes the most appropriate tools, which are performed by the stepwise change of one internal coordinate, while every other coordinates are fully optimized in every step. Relaxed PES calculations are employed, for instance, for the characterization of bond dissociation [5], bond rotation [6], or even the change of electronic structure by varying the phosphorus-metal-phosphorus bond angle [7].

The goal of this paper is to characterize the ligand Xantphos coordinated to the $\mathrm{HCo}(\mathrm{CO})$ moiety. These kinds of complexes can serve as catalysts for the cobalt-catalyzed hydroformylation reaction, containing diphosphine ligands. Besides the discussion of the corresponding Co-Xantphos complex, the bite angle effect is estimated via the complex cis-[HCo(CO) $\left.\left(\mathrm{PPh}_{3}\right)_{2}\right]$ in a flexible potential energy scan, constraining the P-Co-P angle at every step with a full optimization of all other internal coordinates.

\section{Computational Details}

For all the calculations the PBEPBE gradient-corrected functional by Perdew et al. [8] was selected using the Gaussian 09 suite of programs [9]. For the Co atom the triple- $\xi$ basis set by Ahlrichs and coworkers was applied and denoted as TZVP [10], whereas the 6-31G $(\mathrm{d}, \mathrm{p})$ basis set [11] was employed for every other atoms. Local minima were identified by 
TABLE 1: Selected bond lengths in $\mathrm{HCo}(\mathrm{CO})$ (phosphine) complexes as well as those of the structures involved in the PES scan changing the $\mathrm{P}-\mathrm{CO}-\mathrm{P}$ angle. The cis phosphorus atom with respect to the hydride ligand is designated as $\mathrm{P} 1$.

\begin{tabular}{|c|c|c|c|c|c|}
\hline Structure & $r(\mathrm{H}-\mathrm{Co})$ & $r(\mathrm{Co}-\mathrm{P} 1)$ & $r(\mathrm{Co}-\mathrm{P} 2)$ & $r(\mathrm{Co}-\mathrm{C})$ & $r(\mathrm{C}-\mathrm{O})$ \\
\hline $\mathrm{HCo}(\mathrm{CO})\left(\mathrm{PH}_{3}\right)_{2}(2)$ & 1.505 & 2.159 & 2.154 & 1.721 & 1.175 \\
\hline $\mathrm{HCo}(\mathrm{CO})$ (Xantphos) (1) & 1.490 & 2.219 & 2.227 & 1.708 & 1.181 \\
\hline $\mathrm{HCo}\left(\mathrm{CO}\left(\mathrm{PPh}_{3}\right)_{2}(3)\right.$ & 1.503 & 2.203 & 2.191 & 1.716 & 1.180 \\
\hline 3: $\Theta=98.5^{\circ}$ & 1.504 & 2.197 & 2.227 & 1.715 & 1.180 \\
\hline 3: $\Theta=103.5^{\circ}$ & 1.503 & 2.194 & 2.210 & 1.716 & 1.180 \\
\hline 3: $\Theta=108.5^{\circ}$ & 1.498 & 2.210 & 2.195 & 1.717 & 1.180 \\
\hline 3: $\Theta=113.5^{\circ}$ & 1.496 & 2.184 & 2.184 & 1.718 & 1.180 \\
\hline 3: $\Theta=118.5^{\circ}$ & 1.496 & 2.200 & 2.181 & 1.717 & 1.181 \\
\hline 3: $\Theta=123.5^{\circ}$ & 1.486 & 2.180 & 2.166 & 1.720 & 1.181 \\
\hline 3: $\Theta=128.5^{\circ}$ & 1.485 & 2.180 & 2.169 & 1.718 & 1.181 \\
\hline 3: $\Theta=133.5^{\circ}$ & 1.484 & 2.175 & 2.171 & 1.717 & 1.181 \\
\hline 3: $\Theta=138.5^{\circ}$ & 1.481 & 2.173 & 2.170 & 1.178 & 1.180 \\
\hline
\end{tabular}<smiles>Pc1ccccc1Cc1ccccc1-c1ccccc1</smiles>

BISBI

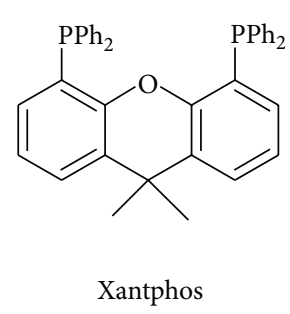

SCHeme 1: Diphosphines BISBI, and Xantphos, possessing wide bite angles.

the absence of the negative eigenvalues in the vibrational frequency analyses, whereas the Hessian matrix of transition states has only one negative eigenvalue. For the QTAIM studies the AIMAll software was employed [12].

\section{Results and Discussion}

The computed structure of $\mathrm{HCo}(\mathrm{CO})$ (Xantphos) (1) is depicted in Figure 1. For a bite angle $112.8^{\circ}$ has been obtained, somewhat less than expected, due to the slightly bent arrangement of the fused rings about the middle ring. The geometry is similar to that of the rhodium analogue $\mathrm{HRh}(\mathrm{CO})$ (Xantphos), reported by Landis and Uddin [13]. For comparison, complexes $\mathrm{HCo}(\mathrm{CO})\left(\mathrm{PH}_{3}\right)_{2}$ (2) and $\mathrm{HCo}(\mathrm{CO})\left(\mathrm{PPh}_{3}\right)_{2}$ (3) are also shown in Figure 1. Not surprisingly, both complexes exhibit smaller bite angles: $103.2^{\circ}$, and $106.5^{\circ}$ for complex 2 and complex 3 , respectively. The C$O$ bond distance of the carbonyl ligand is almost identical in $\mathbf{1}$ and 3, indicating a very similar P-donor character for Xantphos and $\mathrm{PPh}_{3}$ in terms of back-donation from cobalt to the CO ligand. In complex 2 the $\mathrm{CO}$ bond is somewhat shorter suggesting weaker donation ability for $\mathrm{PH}_{3}$ in comparison to both triarylphosphines. Remarkable, however, is the difference in Co-H bond distance in complexes $\mathbf{1}$ and $\mathbf{3}$, proposing a stronger metal-hydride bond in the Xantphoscontaining complex. All complexes exhibit also structures distorted from square planar arrangement; complex $\mathbf{2}$ is the closest to planar. The distortion is illustrated in the inlet in Figure 1, showing the hydride and carbonyl ligands bent from the P-Co-P plane.
The electronic effect in wide bite angle ligands can be divided in two parts: one is the influence of the substituents on phosphorus, whereas the secondary electronic effect is determined by steric effects, that is, the bulk of the substituents, and the phosphorus-metal-phosphorus bite angle. For the interpretation of the secondary effect, a flexible potential energy surface scan has been completed using complex 3 as model compound (see Figure 2). Although the middle ring and especially the oxygen heteroatom slightly alter the electronic structure of $\mathrm{P}$ atoms in complex 1 , triphenylphosphine, as a triarylphosphine, is an appropriate candidate for testing the bite angle effect. This is also supported by computed $v(\mathrm{CO})$ values, as they are very close to each other: 1970 and $1967 \mathrm{~cm}^{-1}$ for 1 and 3, respectively.

The PES scan was done in two directions starting from the equilibrium geometry of 3 , covering the P-Co-P angle (denoted as $\Theta$ ) range from $98.5^{\circ}$ to $138.5^{\circ}$ in $5^{\circ}$ steps. The energy of the $98.5^{\circ}$ structure is higher by only $1.5 \mathrm{kcal} / \mathrm{mol}$ than that of 3 , in spite of the steric congestion of the inner phenyl rings. This may be the consequence of the energy gain caused by $\pi$-stacking interaction between the rings, which partly compensates the steric repulsion. The influence of $\pi$-stacking on the regioselectivity of platinum-containing hydroformylation catalysts was investigated employing the Dreiding force field and it was concluded that the phenyl group of styrene may interact with the aromatic ring of the phosphine ligand increasing the ratio of the branched aldehyde [14].

At $113.5^{\circ}$ a local genuine minimum appears, which is less stable than 3 by only $0.9 \mathrm{kcal} / \mathrm{mol}$. The approximate transition state for this conformational change of the aryl rings emerges at the angle of $108.5^{\circ}$ with a barrier of about $1.2 \mathrm{kcal} / \mathrm{mol}$. This local minimum is a good approximation for $\mathbf{1}$ in terms of bite angle. As the bite angle increased the potential energy also increases, somewhat steeper in the vicinity of the local minimum structure, with an inflexion point at about $108.5^{\circ}$, with a gradual increase until the angle of $123.5^{\circ}$, and with a steeper increase again at bite angles larger than that. The structure with a bite angle of $138.5^{\circ}$ is by $7.6 \mathrm{kcal} / \mathrm{mol}$ higher in energy in comparison to 3.

The structural parameters of all the structures involved in the PES scan are compiled in Table 1. It is shown that 


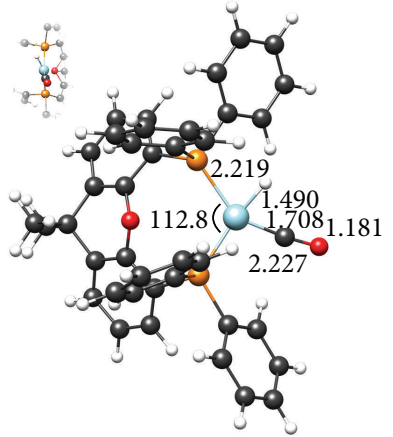

(1)

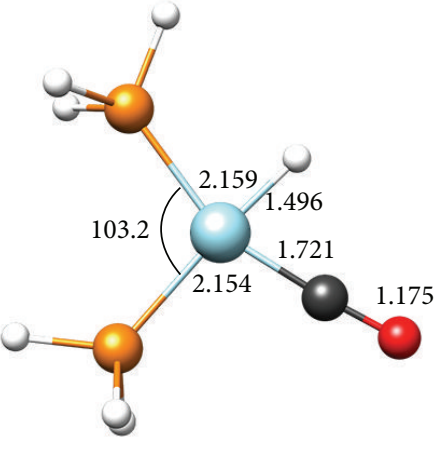

(2)

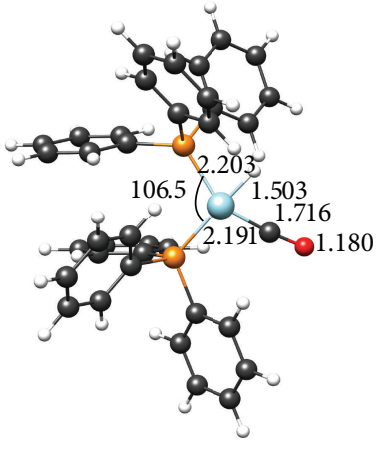

(3)

Figure 1: Computed structure of $\mathrm{HCo}(\mathrm{CO})\left(\right.$ Xantphos) $(1), \mathrm{HCo}(\mathrm{CO})\left(\mathrm{PH}_{3}\right)_{2}(2)$, and $\mathrm{HCo}(\mathrm{CO})\left(\mathrm{PPh}_{3}\right)_{2}(3)$. Bond lengths are given in $\AA$; angles are given in degrees.

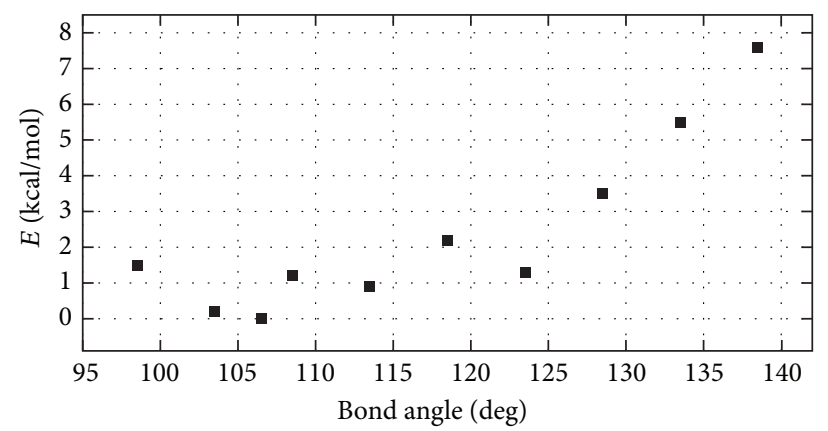

FIgURE 2: The potential energy against the $\mathrm{P}-\mathrm{Co}-\mathrm{P}$ angle in complex cis- $\left[\mathrm{HCo}(\mathrm{CO})\left(\mathrm{PPh}_{3}\right)_{2}\right]$.

the cobalt-hydrogen bond length is closely related to the bite angle: the greater the angle is, the shorter the $\mathrm{Co}-\mathrm{H}$ bond is. No such obvious relationship has been found for the Co-C, and for the $\mathrm{C}-\mathrm{O}$ bonds. On the other hand, the $\mathrm{Co}-\mathrm{P}$ bonds are more elongated for the minimum structures, as well as for that with a bite angle of $98.5^{\circ}$.

The electronic structure around the cobalt central atom has been elucidated within the framework of the Quantum Theory of Atoms in Molecules developed by Bader. One of the two QTAIM descriptors taken into account is the delocalization index $\delta(\mathrm{A}, \mathrm{B})$, which is introduced by Bader and Stephens [15] and describes the number of electron pairs delocalized between two atomic basins. The $\delta(\mathrm{A}, \mathrm{B})$ is somewhat related to formal bond orders for an equally shared pair between two atoms in a polyatomic molecule; however, it is usually less than that due to delocalization over the other atoms in the molecule. The second descriptor is the electron density at bond critical points $\left(\rho_{\mathrm{BCP}}\right)$, which is also related tobond strengths. The $\delta(\mathrm{A}, \mathrm{B})$ data for all structures considered in this study are presented in Table 2 , whereas the $\left(\rho_{\mathrm{BCP}}\right)$ data for them are shown in Table 3.

The relationship between the delocalization index for the $\mathrm{H}-\mathrm{Co}$ bond and the bite angle is not so obvious, than the relationship between the $\mathrm{H}-\mathrm{Co}$ bond lengths and the bite angle. It reaches its minimum at $106.5^{\circ}$ (hence in the case of 3 ) and it gets greater at larger bond angles; however, it has a maximum at $\Theta=123.5^{\circ}$. It is notable that $\delta(\mathrm{H}, \mathrm{Co})$ in complex 1 (which has a bite angle of $112.8^{\circ}$ ) almost matches that for the structure $\mathrm{HCo}(\mathrm{CO})\left(\mathrm{PPh}_{3}\right)_{2}$ with a bite angle of $113.5^{\circ}$ corroborating the close relationship between the bite angle and the $\mathrm{H}-\mathrm{Co}$ bond strength.

The $\delta(\mathrm{C}, \mathrm{O})$ value is directly related to the electronic influence of phosphine upon the $\mathrm{C}-\mathrm{O}$ bond; thus it is somewhat connected with Tolman's electronic parameter [16], which is a widely used descriptor for the characterization of various P-donor ligands. Interestingly, among the bistriphenylphosphino structures, the $\Theta=133.5^{\circ}$ structure provides the closest match with the Xantphos-containing complex 1. Otherwise, the delocalization index of the $\mathrm{C}-\mathrm{O}$ bond reveals a continuous decrease in the function of bite angle, indicating that the donor character of the $\mathrm{PPh}_{3}$ ligand is stronger when the bite angle is increased.

The electron density at bond critical points is, however, less indicative for the description of bite angle effect. For the $\mathrm{Co}-\mathrm{C}$ and $\mathrm{C}-\mathrm{O}$ bonds only a very subtle change can be observed. The value of $\rho_{\mathrm{BCP}}(\mathrm{H}-\mathrm{Co})$ moves in a very narrow range as well; however, it shows an increasing trend along with the increase of the bite angle, in conjunction with the delocalization index $\delta(\mathrm{C}, \mathrm{O})$.

From the electron density distribution within a molecule, detailed information can be obtained by the Laplacian of electron density, $\nabla^{2} \rho(\mathbf{r})<0$, which indicates charge concentrations of charge depletions. The Laplacian distribution of $\mathbf{2}$, as a prototype species, is depicted in Figure 3. Both 
TABLE 2: Delocalization indices $\delta(\mathrm{A}, \mathrm{B})$ in complexes 1-3, as well as that for the structures resulted in the $\mathrm{PES} \operatorname{scan}$ of $\mathrm{HCo}(\mathrm{CO})(\mathrm{PPh})_{2}$.

\begin{tabular}{|c|c|c|c|c|c|}
\hline Structure & $\delta(\mathrm{H}, \mathrm{Co})$ & $\delta(\mathrm{Co}, \mathrm{P} 1)$ & $\delta(\mathrm{Co}, \mathrm{P} 2)$ & $\delta(\mathrm{Co}, \mathrm{C})$ & $\delta(\mathrm{C}, \mathrm{O})$ \\
\hline $\mathrm{HCo}(\mathrm{CO})$ (Xantphos) (1) & 0.767 & 0.829 & 0.798 & 1.411 & 1.497 \\
\hline $\mathrm{HCo}(\mathrm{CO})\left(\mathrm{PH}_{3}\right)_{2}(2)$ & 0.802 & 0.942 & 0.866 & 1.352 & 1.533 \\
\hline $\mathrm{HCo}(\mathrm{CO})\left(\mathrm{PPh}_{3}\right)_{2}(3)$ & 0.748 & 0.876 & 0.826 & 1.383 & 1.506 \\
\hline 3: $\Theta=98.5^{\circ}$ & 0.764 & 0.871 & 0.789 & 1.392 & 1.509 \\
\hline 3: $\Theta=103.5^{\circ}$ & 0.755 & 0.874 & 0.816 & 1.386 & 1.508 \\
\hline 3: $\Theta=108.5^{\circ}$ & 0.771 & 0.847 & 0.844 & 1.374 & 1.508 \\
\hline 3: $\Theta=113.5^{\circ}$ & 0.768 & 0.848 & 0.870 & 1.374 & 1.506 \\
\hline 3: $\Theta=118.5^{\circ}$ & 0.754 & 0.855 & 0.871 & 1.372 & 1.503 \\
\hline 3: $\Theta=123.5^{\circ}$ & 0.796 & 0.804 & 0.925 & 1.370 & 1.502 \\
\hline 3: $\Theta=128.5^{\circ}$ & 0.790 & 0.808 & 0.920 & 1.371 & 1.499 \\
\hline 3: $\Theta=133.5^{\circ}$ & 0.785 & 0.811 & 0.918 & 1.367 & 1.496 \\
\hline 3: $\Theta=138.5^{\circ}$ & 0.789 & 0.812 & 0.920 & 1.355 & 1.500 \\
\hline
\end{tabular}

TABLE 3: Electron density at bond critical points $\rho_{\mathrm{BCP}}(\mathrm{A}-\mathrm{B})$ in complexes $\mathbf{1}-\mathbf{3}$, as well as that for the structures resulted in the PES scan of $\mathrm{HCo}(\mathrm{CO})\left(\mathrm{PPh}_{3}\right)_{2}$.

\begin{tabular}{|c|c|c|c|c|c|}
\hline Structure & $\rho_{\mathrm{BCP}}(\mathrm{H}-\mathrm{Co})$ & $\rho_{\mathrm{BCP}}(\mathrm{Co}-\mathrm{P} 1)$ & $\rho_{\mathrm{BCP}}(\mathrm{Co}-\mathrm{P} 2)$ & $\rho_{\mathrm{BCP}}(\mathrm{Co}-\mathrm{C})$ & $\rho_{\mathrm{BCP}}(\mathrm{C}-\mathrm{O})$ \\
\hline $\mathrm{HCo}(\mathrm{CO})\left(\mathrm{PH}_{3}\right)_{2}(2)$ & 0.129 & 0.093 & 0.093 & 0.172 & 0.429 \\
\hline $\mathrm{HCo}(\mathrm{CO})($ Xantphos) (1) & 0.129 & 0.088 & 0.088 & 0.177 & 0.423 \\
\hline $\mathrm{HCo}(\mathrm{CO})\left(\mathrm{PPh}_{3}\right)_{2}(3)$ & 0.126 & 0.092 & 0.092 & 0.173 & 0.424 \\
\hline 3: $\Theta=98.5^{\circ}$ & 0.126 & 0.091 & 0.088 & 0.174 & 0.424 \\
\hline 3: $\Theta=103.5^{\circ}$ & 0.126 & 0.092 & 0.091 & 0.173 & 0.424 \\
\hline $3: \Theta=108.5^{\circ}$ & 0.132 & 0.095 & 0.098 & 0.174 & 0.423 \\
\hline 3: $\Theta=113.5^{\circ}$ & 0.128 & 0.090 & 0.096 & 0.173 & 0.423 \\
\hline $3: \Theta=118.5^{\circ}$ & 0.128 & 0.092 & 0.096 & 0.174 & 0.423 \\
\hline 3: $\Theta=123.5^{\circ}$ & 0.132 & 0.094 & 0.098 & 0.172 & 0.423 \\
\hline 3: $\Theta=128.5^{\circ}$ & 0.132 & 0.094 & 0.098 & 0.173 & 0.423 \\
\hline 3: $\Theta=133.5^{\circ}$ & 0.132 & 0.095 & 0.098 & 0.174 & 0.423 \\
\hline 3: $\Theta=138.5^{\circ}$ & 0.133 & 0.095 & 0.098 & 0.173 & 0.424 \\
\hline
\end{tabular}

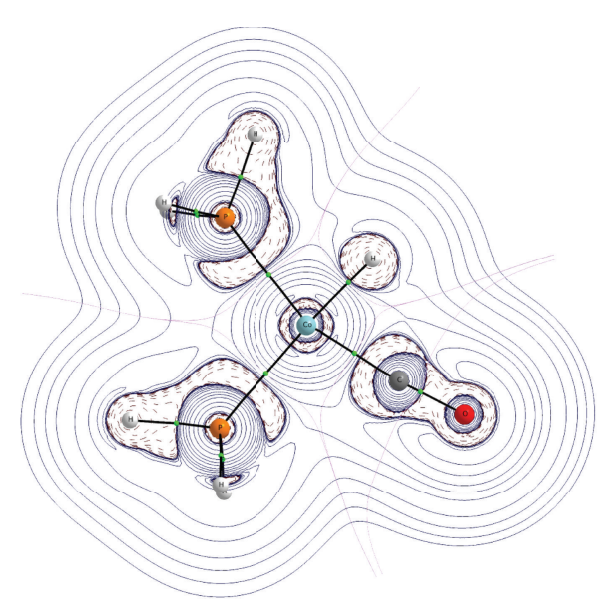

Figure 3: Contour-line diagram of the Laplacian distribution of complex 2. Solid lines indicate charge depletions $\left[\nabla^{2} \rho(\mathbf{r})>0\right]$, dashed lines indicate charge concentrations $\left[\nabla^{2} \rho(\mathbf{r})<0\right]$.

$\mathrm{PH}_{3}$ ligands and the carbonyl ligand show the well-known Lewis-base character which can be attributed to their lone pairs oriented toward the cobalt central atom. The $\mathrm{Co}-\mathrm{H}$ bond reveals a strong polarity, as reflected by the charge concentration around $\mathrm{H}$, and the charge depletion around $\mathrm{Co}$, and these two regions are separated almost by the bordering surface between the two atomic basins. The strong distortion in the electron density distribution of cobalt in the region between the hydride and the neighboring $\mathrm{PH}_{3}$ ligands might reflect the sensitivity of $\mathrm{Co}-\mathrm{H}$ bond strength to the change of the P-Co-P angle.

\section{Conclusion}

The increase of the bite angle results in an enhancement of the strength of the $\mathrm{H}-\mathrm{Co}$ bond, whereas the $\mathrm{C}-\mathrm{O}$ bond in the carbonyl ligand becomes somewhat weaker revealing an increase also in the $\sigma$-donor character of the phosphine ligand. The model compound cis-[HCo $\left.(\mathrm{CO})\left(\mathrm{PPh}_{3}\right)_{2}\right]$ shows a flexibility both in terms of energy and in terms of electronic structure upon the change of the P-Co-P angle, which indicates a rather flexible behavior of $\mathrm{PPh}_{3}$ ligands in real reaction conditions. 


\section{Conflict of Interests}

The authors declare that there is no conflict of interests regarding the publication of this paper.

\section{References}

[1] C. P. Casey and G. T. Whiteker, "The natural bite angle of chelating diphosphines," Israel Journal of Chemistry, vol. 30, no. 4, pp. 299-304, 1990.

[2] M. Kranenburg, Y. E. M. van der Burgt, P. C. J. Kamer, P. W. N. M. van Leeuwen, K. Goubitz, and J. Fraanje, "New diphosphine ligands based on heterocyclic aromatics inducing very high regioselectivity in rhodium-catalyzed hydroformylation: effect of the bite angle," Organometallics, vol. 14, no. 6, pp. 3081-3089, 1995.

[3] P. W. N. M. van Leeuwen, P. C. J. Kamer, and J. N. H. Reek, "The bite angle makes the catalyst," Pure and Applied Chemistry, vol. 71, no. 8, pp. 1443-1452, 1999.

[4] H. B. Schlegel, "Exploring potential energy surfaces for chemical reactions: an overview of some practical methods," Journal of Computational Chemistry, vol. 24, no. 12, pp. 1514-1527, 2003.

[5] T. Kégl and F. Ungváry, "The cobalt-catalyzed ketene formation from diazoalkanes," Letters in Organic Chemistry, vol. 7, pp. 634-644, 2010.

[6] T. E. Barder, M. R. Biscoe, and S. L. Buchwald, "Structural insights into active catalyst structures and oxidative addition to (biaryl)phosphine-palladium complexes via density functional theory and experimental studies," Organometallics, vol. 26, no. 9, pp. 2183-2192, 2007.

[7] T. Kégl, R. Ponec, and L. Kollár, "Theoretical insights into the nature of nickel-carbon dioxide interactions in $\mathrm{Ni}\left(\mathrm{PH}_{3}\right)_{2}\left(\eta^{2}\right.$ $\left.\mathrm{CO}_{2}\right)$," The Journal of Physical Chemistry A, vol. 115, no. 45, pp. 12463-12473, 2011.

[8] J. P. Perdew, K. Burke, and M. Ernzerhof, "Generalized gradient approximation made simple," Physical Review Letters, vol. 77, no. 18, pp. 3865-3868, 1996.

[9] M. J. Frisch, G. W. Trucks, H. B. Schlegel et al., Gaussian 09 Revision C. 01, Gaussian Inc., Wallingford CT, 2009.

[10] A. Schaefer, C. Huber, and R. J. Ahlrichs, "Fully optimized contracted Gaussian basis sets of triple zeta valence quality for atoms Li to Kr," The Journal of Chemical Physics, vol. 100, p. 5829, 1994.

[11] R. Ditchfield, W. J. Hehre, and J. A. Pople, "Self-consistent molecular-orbital methods. IX. an extended Gaussian-type basis for molecular-orbital studies of organic molecules," The Journal of Chemical Physics, vol. 54, p. 724, 1971.

[12] AIMAll [Version 13. 05. 06], Todd A. Keith, TK Gristmill Software, Overland Park, Kan, USA, 2013, http://aim.tkgristmill .com.

[13] C. R. Landis and J. Uddin, "Quantum mechanical modelling of alkene hydroformylation as catalyzed by xantphos-Rh complexes," Dalton Transactions, no. 5, pp. 729-742, 2002.

[14] L. A. Castonguay, A. K. Rappé, and C. J. Casewit, "pi-Stacking and the platinum-catalyzed asymmetric hydroformylation reaction: a molecular modeling study," Journal of the American Chemical Society, vol. 113, p. 7179, 1991.

[15] R. F. W. Bader and M. E. Stephens, "Spatial localization of the electronic pair and number distributions in molecules," Journal of the American Chemical Society, vol. 97, no. 26, pp. 7391-7399, 1975.
[16] C. A. Tolman, "Steric effects of phosphorus ligands in organometallic chemistry and homogeneous catalysis," Chemical Reviews, vol. 77, no. 3, pp. 313-348, 1977. 



\section{Carbohydrate} Chemistry

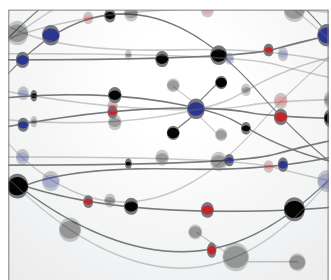

The Scientific World Journal

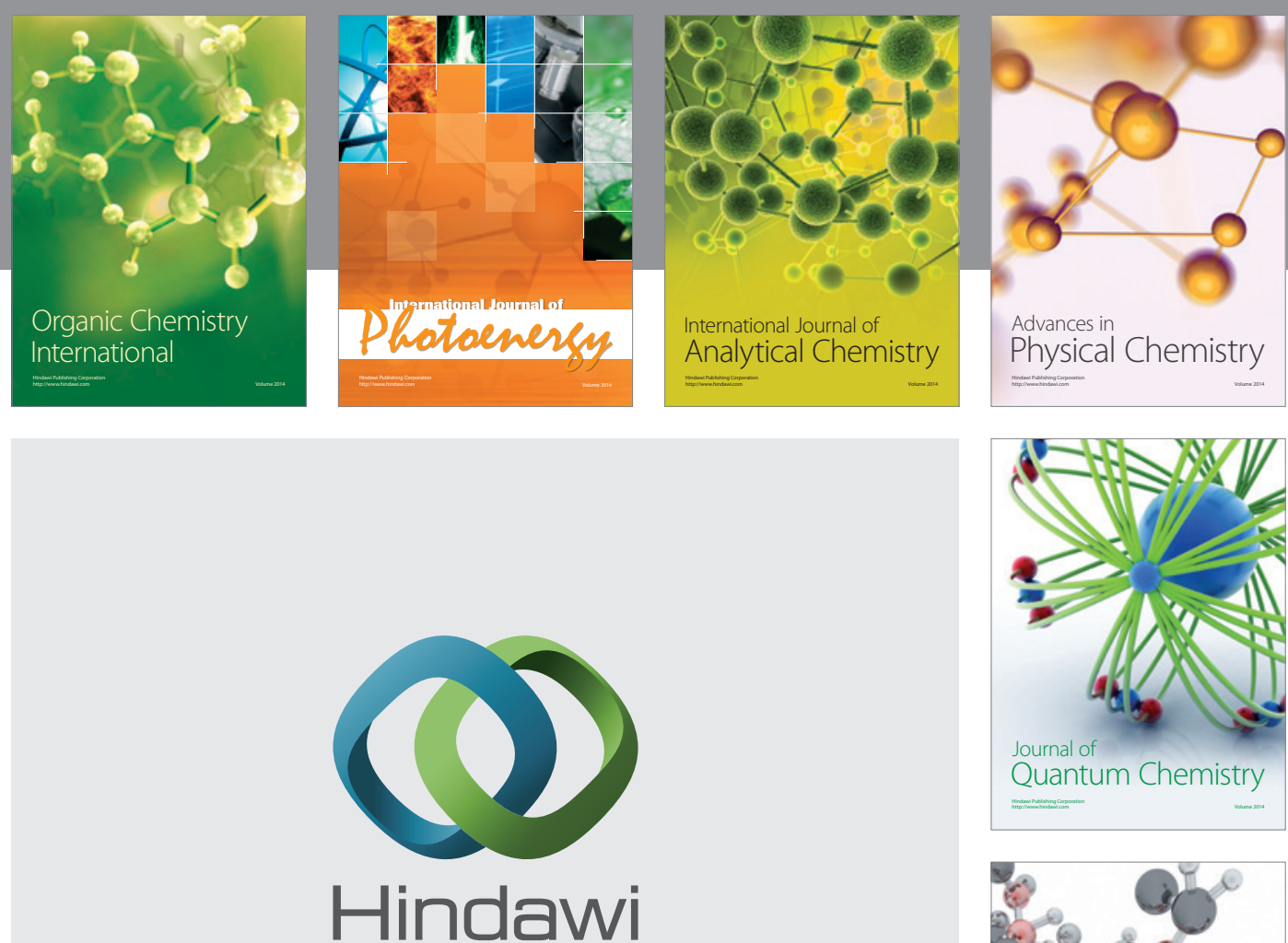

Submit your manuscripts at

http://www.hindawi.com

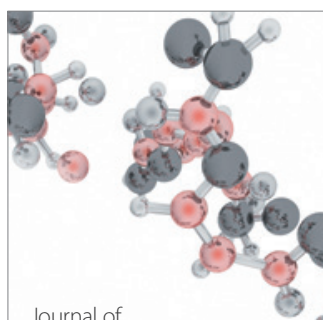

Analytical Methods

in Chemistry

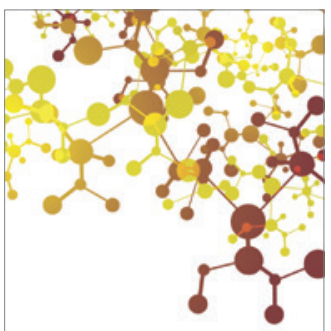

Journal of

Applied Chemistry

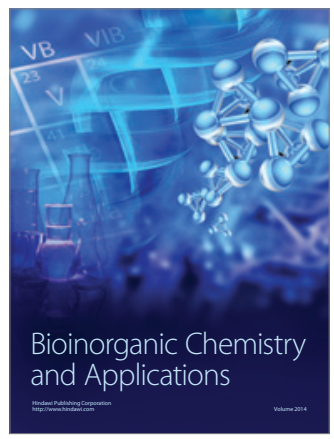

Inorganic Chemistry
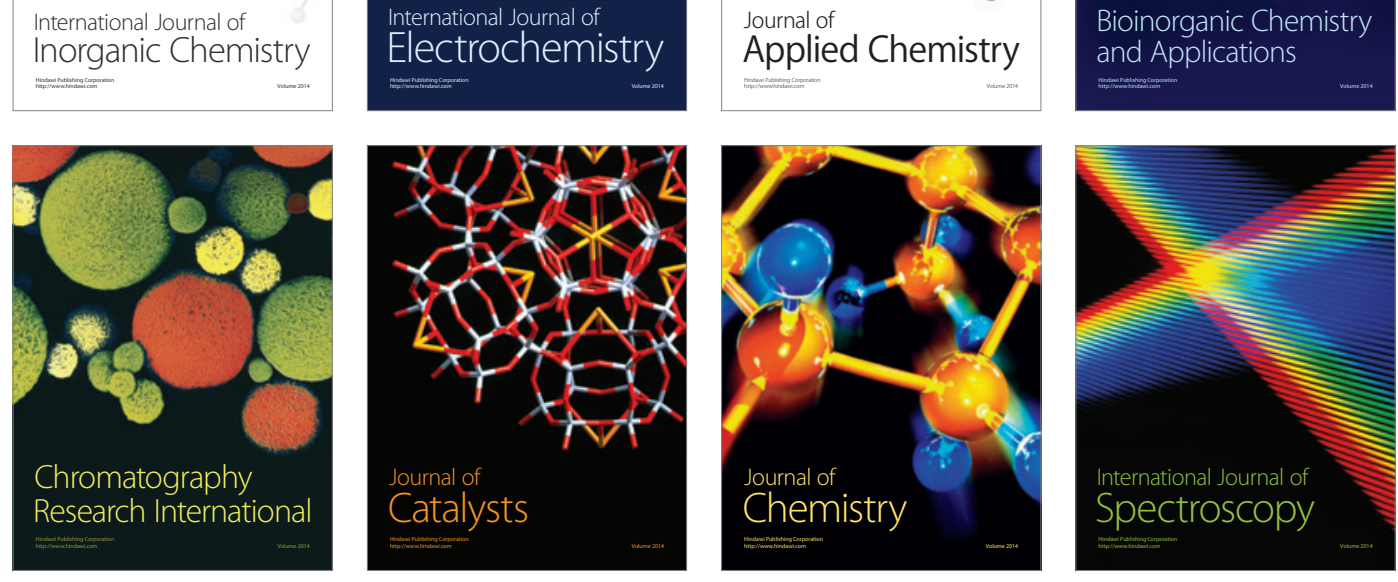